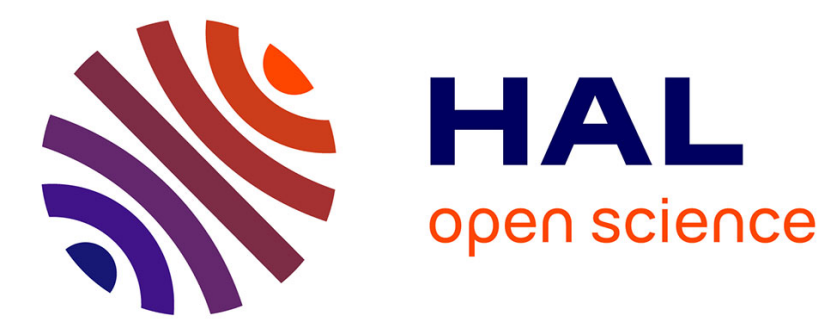

\title{
Environmental and Social Impacts of Mass Customization: An Analysis of Beginning-of-Life Phases
}

Golboo Pourabdollahian, Frank Steiner

\section{To cite this version:}

Golboo Pourabdollahian, Frank Steiner. Environmental and Social Impacts of Mass Customization: An Analysis of Beginning-of-Life Phases. IFIP International Conference on Advances in Production Management Systems (APMS), Sep 2014, Ajaccio, France. pp.526-532, 10.1007/978-3-662-447369_64. hal-01387928

\section{HAL Id: hal-01387928 \\ https://hal.inria.fr/hal-01387928}

Submitted on 26 Oct 2016

HAL is a multi-disciplinary open access archive for the deposit and dissemination of scientific research documents, whether they are published or not. The documents may come from teaching and research institutions in France or abroad, or from public or private research centers.
L'archive ouverte pluridisciplinaire HAL, est destinée au dépôt et à la diffusion de documents scientifiques de niveau recherche, publiés ou non, émanant des établissements d'enseignement et de recherche français ou étrangers, des laboratoires publics ou privés. 


\title{
Environmental and social impacts of Mass Customization: An analysis of Beginning-of-Life phases
}

\author{
Golboo Pourabdollahian ${ }^{1}$, Frank Steiner ${ }^{2}$ \\ ${ }^{1}$ CNR-ITIA, Via Bassini 15, 20133, Milan, Italy \\ ${ }^{2}$ RWTH Aachen University, Technology and Innovation Management Group, Aachen, \\ Germany \\ golboo.pourabdollahian@itia.cnr.it, steiner@tim.rwth-aachen.de
}

\begin{abstract}
For about two decades Mass customization (MC) has been broadly discussed as a proper business model to satisfy heteregenous needs of customers in an efficient manner.However, the increasing importance of other trends such as sustainability make it inevitable for MC companies to operate in an eco-friendly and socially-friendly way. This paper aims investigating and identifying of potential impact factors of Mass Customization on environmental and social sustainability following a Product Lifecycle management (PLM) approach.
\end{abstract}

Keywords: Mass Customization (MC), Sustainability, Beginning of Life (BOL)

\section{Introduction}

From its early introduction as a strategy, Mass Customization (MC) has significantly changed the market offer and value proposition for customers. The concept of Mass Customization emerged to deal with high levels of heterogeneity of the customers' needs [1]. In the other words, Mass Customization can be seen as a hybrid competitive strategy attempting to provide customers with individualized products in a costefficient manner [2]. Accordingly MC benefits the firm through profit generation thanks to the premium price. Mass Customization can be considered as an economically viable strategy since it create revenues and thus profit through turning heterogeneities of customers' needs to an opportunity to create value [3] while the cost level can be kept in a level comparable to mass produced products thanks to implementation of flexible manufacturing processes and suitable customer interaction tools.

Although evaluation of MC from an economic point of view is crucial for success of a MC firm but it is not sufficient considering other challenges that the global community face today. In this regard sustainability is considered as one of the main concerns of manufacturing companies operating in different sectors and applying different strategies. Accordingly, MC enterprises need to take steps toward being more sustainable

adfa, p. 1, 2011.

(C) Springer-Verlag Berlin Heidelberg 2011 
through development of a "Win-Win-Win" strategy which is sustainable not only from economic point of view but also from social and environmental perspectives [4].

Nevertheless, the existing body of literature concerning MC and sustainability is extremely narrow and non-mature. There are very few studies, mainly conceptual, investigating the role of $\mathrm{MC}$ for environmental and social sustainability $[5,6,7]$. The existing gap in this regard opens up interesting research streams that can be studied to support companies in implementing MC in a more sustainable manner. Accordingly, this paper aims at investigating and identifying of potential impact factors of Mass Customization on environmental and social sustainability following a Product Lifecycle management (PLM) approach. The paper is specifically focused on potential environmental and social impacts of MC during the three main phases of beginning of life of a product life cycle namely design, manufacturing and distribution.

\section{Beginning of Life within the product lifecycle approach}

The main objective of Product Lifecycle Management (PLM) is to all the activities and processes along the whole product lifecycle phases which consists of three phases: Beginning of Life (BOL) concerning design, manufacturing, and distribution; Middle of Life (MOL) concerning usage and maintenance; and End of Life (EOL) concerning waste management strategies [8]. Within the product lifecycle, the BOL phase is considered as a critical phase due to its future impacts on the two other phases of MOL and EOL. The decisions which are made during the beginning of life (e.g. design phase) affect significantly on both MOL and EOL of a product. On one hand the final peformance of the product during its use phase is extremely dependent on its design [9], while on the other hand the proper waste management strategy depends on structure of the product the way it is manufactured.

Considering the importance of $\mathrm{BOL}$, in this paper we invetigate the potential influences of $\mathrm{MC}$ on environmental and social sustainability during the beginning of life. In particular the impact factors are identified within the three phases of design, manufacturing and distribution. It should be noticed that the impact factors include both positive and negative ones considering that while some aspects of MC can be beneficial for sustainability, there are some other aspects which might affect negatively the environmental and social performance.

\subsection{Impact Factors in the Design Phase}

In the context of Mass Customization, the approach to product design differs rather strongly from the design of mass produced goods: the strategy of MC aims at integrating the customer throughout all phases of the PLC and thus includes a strong firmcustomer-collaboration during the design phase. This process of co-designing products enables the customers to articulate their individual needs and specifications for the respective product [10]. The involvement of the customer in the design phase potentially enhances social and environmental aspects of sustainability: from a social perspective, this early integration of customers may enable a better consideration of the functional needs of specific interest groups such as elderly users or disabled peo- 
ple, etc. From an environmental perspective, the collaboration with customers in the design phase bears two major impact factors: firstly, being part of the product configuration process provides customers with a learning opportunity concerning the environmental impacts of their feature selection and thus increases the customer awareness of environmental sustainability [11]. Consequently, providing customers with enough information on the environmental impact of certain product attributes during the co-design process can help the users to understand the sustainability impact of their individual choices and thus ultimately supports the design of more eco-friendly products. Secondly, the integration of customers in the design phase, protects manufacturers from implementing an excessive feature load in their products: The codesign process helps to select product attributes, which are strongly aligned with the specific customer needs in a respective market. Subsequently, co-designing with customers helps MC companies to manufacture only such products that are needed and requested by the customers and thereby avoids wasting resources for the integration of unnecessary product features [11].

Beside the co-design process itself, the aspect of modularity has to be considered in the context of the product design phase. MC products are usually characterized by the use of modular product architectures, as modularity serves as one of the main operational enablers of Mass Customization. A modular architecture enables manufacturers to produce a large number of varieties by using different combinations of product modules. That way, modularity allows manufacturers to benefit from economies of scale and reductions in production lead-time, even though mass customization typically requires firms to reduce lot sizes and standardization [12]. However, besides this large economic benefit of modularity, the use of modular product architectures also carries environmental implications: whereas a modular product might be more environmentally-friendly in terms of maintenance and its end-of-life treatment, it carries negative environmental impacts for the product design. Modular products are always inferior to integrated product designs in terms of weight and performance. Hence, more material resources are required for a product that is designed in a modular way $[13,14]$.

Lastly, an additional negative effect of MC can be assumed with regard to product design: the design phase is not only the initial stage of a product lifecycle, but can also be regarded as an essential step in a closed-loop lifecycle that merges the BOL of a new product with the end of life of a former product [15]. In this context, the implementation of a closed-loop lifecycle can be realized more easily in a mass production system than in the context of MC, as mass production deals with more standardized products. Whereas the combination of the EOL product and the new product is standardized in mass production, a mass customizer will be confronted with new combinations of old and new products with every customer.

\subsection{Impact Factors in the Manufacturing Phase}

Typically, manufacturing companies focus on waste reduction during production, when they pursue the issues of environmental and social sustainability for the first time. According to the National Council of Advanced Manufacturing (2009) sustainable manufacturing refers to the "creation of manufactured products that use processes 
that are non-polluting, conserve energy and natural resources, and are economically sound and safe for employees, communities, and consumers" [16].

Similar to the situation in the design phase, the implementation of Mass Customization shows controversial effects on the manufacturing processes in terms of environmental and social sustainability. However, it has to be noted, that the most important environmental impact factor of MC can be observed in the context of manufacturing: most MC companies operate a so-called X-to-order fulfillment strategy. This means that products are produced only after a respective order has been received from the customer. This approach prevents overproduction, as only those goods are manufactured that are actually needed by the customers. This results not only in a significant decrease of waste in terms of unwanted products, but also in a much lower level of energy consumption for the overall production. According to a 2009 estimation, 300 million pairs of shoes are over produced each year. Considering the energy required to produce each pair of shoes, the total energy consumption to manufacture all these unsold pairs of shoes equals $14 \%$ of the annual energy consumption of Switzerland [17]. This study shows that Mass Customization indeed has a major beneficial impact on sustainability in terms of manufacturing.

On the other hand - as mentioned above - there are also negative aspects to MC manufacturing. For example, it has to be acknowledged that the realization of customized goods typically consumes more energy and resources than the manufacturing of massproduced products. Coming back to the example of shoes, every customized pair requires an individual type and cut of the leather, while for a standard pair of shoes the same type and cut of leather can be used. In consequence, manufacturing processes and the usage of raw material can be optimized in mass production and overall a lower consumption of raw materials and energy can be realized [18]. Hence, the increase of manufacturing complexity that results from an increase in product variety leads to a negative environmental impact of MC.

Besides these environmental aspects, the implementation of Mass Customization also shows social impacts in the manufacturing phase: whereas the rise of mass production has led to an increased used of offshoring of manufacturing, it can be observed that MC oftentimes goes along with more localized manufacturing concepts. As the products in MC are highly customized, fast response times and local distribution channels are of higher importance for manufacturers than in the context of mass production. Therefore, the implementation of Mass Customization carries the beneficial social impact factor of building and protecting a healthy, local job base.

\subsection{Impact Factors in the Distribution Phase}

Due to its typical $\mathrm{x}$-to-order fulfillment strategies, the implementation of MC also requires new approaches for the distribution of final products, which in turn result in particular impacts on environmental sustainability. As in most cases of MC production can only start after the customer order has been placed, the customer cannot directly receive the product at the point of sale. Thus - irrespective of whether the order was placed in a store or via an online sales channel - most MC companies have to realize home delivery for individual products. Naturally, such individual shipments of 
products require additional resources in terms of packaging and energy consumption $[18,14]$. Moreover, this single batch delivery also leads to the consequence that each product is shipped individually, instead of transporting a larger batch of products to a store or distribution warehouse. Subsequently, a higher number of delivery operations is needed and hence more transportation emissions have to be expected. On the other hand, if MC was realized as an online retail business, customers do not have to travel to a store for picking up the final product. This suggests that MC may also have a positive environmental effect in terms of the distribution phase [18].

Additionally, the overall environmental impact of the distribution phase depends largely on the distance between the production site and the respective customers. A study by Kleer and Steiner, for example, shows that for a manufacturer of individualized shoes the individual shipment of products from the production site in China to the customers in Europe makes up a considerable part of the overall $\mathrm{CO}_{2}$ emissions of this specific business model [6]. However, if MC is realized in combination with a localized production - for example in the form of so called micro factories [39] - the negative environmental effect of individual distribution can be strongly mitigated. In such a case, the distribution distance could be reduced significantly and would result in lower energy consumption and less emissions during the distribution phase [20].

Lastly, the impact of reverse logistics is a critical point with regard to the distribution phase. Generally speaking, MC companies enjoy a less complicated distribution system in terms of reverse logistics: as MC products are tailored to the specific needs of individual customers, it is rather difficult to apply a return policy for these products. The lack of such a return policy has its own controversial impacts in terms of environmental sustainability: on one hand, companies do not have to deal with reverse logistics, as customers cannot return the goods. This significantly reduces the level of energy consumption and transportation emissions. On the other hand, the lack of a return policy could also result in an increase in the level of waste: a customized product that does not meet the expectations of the customer, for whom it was customized, will most likely be disposed without being used, because it simply is not compatible with the needs of any other customer. This limitation towards re-use of the product may thus be regarded as a negative impact that results from the specific role of reverse logistics in mass customization.

\section{Conclusion}

Mass customization is mainly recognized as strategy to fulfill the individual needs of the customers in an efficient manner. The increasing interest of customers in involvement in the design phase and creating a customized product has made MC a proper business model and an attractive trend for many companies. Nevertheless for most companies, specially manufacturing companies, it is not the only trend to be followed. The increasing importance of sustainability both among customers and governments has pinpointed it as a critical point of attention for manufacturing companies including MC firms. In this paper we try to target this topic by having a closer look to the concept of Mass Customization from the sustainability point of view, both environmental and social. The paper tries to discover the potential interdependencies 
between MC and sustainability and eventually explore the environmental and social impacts of Mass customization. Following the product lifecycle management approach, the study is particularly focused on the beginning of life of MC products consisting of three main stages namely, design, manufacturing, and distribution.

The analysis reveals that while in some aspects MC can act as a positive driving force for sustainability, in some another aspects it could cause challenges for sustainability. For instance, from an environmental point of view, the modular architecture of a MC product can be seen as a significant positive driver for sustainability positive impact factor for sustainability due to facilitating of disassembly and therefore implementation of sustainable waste management strategies such as re-manufacturing and redesign at the end of the life of the product. However, from a different perspective, the customized nature of MC products makes them very single customer oriented and approximately impossible to be re-used by another customer. The elimination of reusing as a proper waste management strategy at the EOL phase, would lead to an increase in waste and a shorter lifespan of the MC products.

On the other hand, from a social perspective MC seems to be a more a positive driving force. Thanks to the co-design process, the strategy benefits customers, especially those with special needs (i.e. disabled customers), through providing them with products which are designed to satisfy their specific requirements in terms of function, performance or aesthetic. Meanwhile it would result in creation of more local jobs. Consequently, it is not possible to label Mass Customization as a sustainable or nonsustainable strategy. The environmental and social impacts of Mass Customization mark it as a bilateral business model. In fact, the challenge for the MC enterprise is to realize the trade-off and try to implement $\mathrm{MC}$ in a more sustainable manner.

\section{References}

[1] S. M. Davis, Future Perfect. Reading: Addison-Wesley, 1987.

[2] F. T. Piller, Mass Customization: ein wettbewerbsstrategisches Konzept im Informationszeitalter, 2. ed. Wiesbaden: Gabler, 2001.

[3] F. T. Piller and F. Steiner, "Mass Customization as an Enabler of Network Resilience," in Intelligent Non-hierarchical Manufacturing Networks, R. Poler, et al., Eds., ed Hoboken: John Wiley \& Sons, pp. 3-22, 2013.

[4] J. Elkington, "Towards the Sustainable Corporation: Win-Win-Win Business Strategies for Sustainable Development," California Management Review, Vol. 36, No. 2, Winter94, pp. 90100, 1994.

[5] D. Pollard, S. Chuo, and B. Lee, "Strategies For Mass Customization," Journal of Business \& Economics Research, Vol. 6, No. 7, pp. 77-86, 2008.

[6] R. Kleer and F. Steiner, "Mass Customization: Bridging Customer Integration and Sustainability? (Working Paper)," Available at SSRN: http://ssrn.com/abstract=2245622.

[7] C. R. Boër, P. Pedrazzoli, A. Bettoni, and M. Sorlini, Mass customization and sustainability: an assessment framework and industrial implementation. London: Springer, 2013. 
[8] A. Matsokis, D. Kiristis, "An ontology-based approach for Product Lifecycle Management," Computer in Industry, Vol. 61, pp. 787-797, 2010.

[9] P. G. Maropoulos and D. Ceglarek, "Design verification and validation in product lifecycle" CIRP Annals - Manufacturing technology, Vol. 59, No. 2, pp. 740 - 759, 2010.

[10] F. T. Piller, P. Schubert, M. Koch, K.M. Möslein, "From mass customization to collaborative co-design," Proceedings of the European Conference on Information Systems (ECIS), Turku, Finland, 2004

[11] F. Badurdeen and J. P. Liyanage, "Sustainable value co-creation through mass customisation: a framework," International Journal of Sustainable Manufacturing, Vol. 2, No. 2/3, pp. 180-203, 2011.

[12] T. Blecker, and G. Friedrich, Mass customization: challenges and solutions. Boston (MA): Springer International Series, 2006.

[13] K. T. Ulrich, and S. D. Eppinger, Product design and development. 3rd ed. New York: McGraw Hill, 2004.

[14] T. D. Petersen, K. Nielsen, S. Taps, K. A. Jørgensen, "Is mass customization sustainable?," Proceedings of the 6th International Conference on Mass Customization, personalization and co-creation (MCPC 2011), San Francisco, US, 2011.

[15] G. Clark, , J. Kosoris, L. N. Hong, M. Crul, "Design for Sustainability: Current Trends in Sustainable Product Design and Development," Journal of Sustainability, Vol. 1, No. 3, pp. 409-424, 2009.

[16] National Council for Advanced Manufacturing, Sustainable Manufacturing. http://www.nacfam.org/, 2009.

[17] C. Boer, "International cooperation on sustainable manufacturing," Presentation at the ICT for Energy Efficiency Conference, 19-20 March, Brussels, Belgium, 2009.

[18] T. D. Brun $\varnothing$, K. Nielsen, S. B. Taps, K. A. Jørgensen, "Sustainability evaluation of mass customization," Advances in Production Management Systems - Sustainable Production and Service Supply Chains, IFIP Advances in Information and Communication Technology, Vol. 414, pp. 175-182, 2013.

[19] G. Pourabdollahian, M. Taisch, and G. Tepe, "Exploring different faces of Mass Customization in Manufacturing," Advances in Production Management Systems - Sustainable Production and Service Supply Chains, IFIP Advances in Information and Communication Technology, Vol. 414, pp. 13-20, 2013.

[20] R. Reichwald, C. M. Stokto, F. T . Piller, "Distributed mini-factory networks as a real-time enterprise: concept, flexibility potential and case studies," In The practical real time enterprise. Berlin - Heidelberg: Springer. pp. 403-434, 2005. 